\title{
Etiological Profile of Stroke and its Relation with the Prothrombotic States
}

Sir,

I compliment Makhija et al for the study carried out to reveal the etiological profile of stroke and its relation with the prothrombotic states.( Indian Journal of Pediatrics 2008; 75(6): 579-84. This study is one of its kinds and very few have been carried out in India on this subject. Though, the author has comprehensively dealt with the subject matter, there are few issues regarding method of data collection which require further clarifications.

Prior to any clinical trial it is important to match case and control group in order to avoid bias. The number of subjects in both the groups in above mentioned study is not properly matched. However, if it was done then the criteria on which the two groups were matched is not clearly explained.

The study was carried out at a tertiary center therefore many cases of hemorrhagic stroke which has maximum mortality in first few hours must have been missed. The inclusion of these cases would have contributed to valuable information regarding the etiology.

Lastly, though the study has been meticulously conducted, the sample size is too small to draw any conclusion. Perhaps a larger sample size can bring about more facts under the scanner.

Rahul Sinha

Department of Pediatrics

Command Hospital (Air Force)

Agaram Post, Bangalore-560007

Karnataka, India Ph: 09886573382

E-mail:drrahul_2000@yahoo.com

\section{REFERENCES}

1. Fullerton HJ, Cherkovitch DM, Wu YW et al. Deaths from Stroke in US Children, 1979-1998. Neurology 2002;59:3439.

2. Steen RG, Xiong $X$, Langston JW et al. Brain Injury in Children with Sickle Cell Diseases. Prevalence and etiology. Ann Neurol 2003; 54: 564-572.

\section{Author's Reply}

Sir,

We thank Dr Sinha for his valuable comments. In our study age mathched healthy controls were taken for creating range of normal referance values for hematological parameters like protein C, Protein S, AT 3 etc, because like coagulation profile, values of these parameters are assessed compared to normal healthy controls.

We agree with Dr Sinha that many cases of hamorrhagic stroke have been missed probably because of high mortality in first few hours and also because of ours being a medical unit without neurosurgical faculty, so pateints with trauma and hemorrhage requiring

surgical grainage were not reffered to us.

The present study included pateints aged 1 month to 12 years coming to a tertiary hospital over a period of one year. As the stroke in newborn and those occuring on background of overtcentral nervous system infection have been excluded, this further reduced eligible candidate for incursion in the study. Definitely a study with larger sample size would provide more insight into the problem.

Sonia Makhija

B-3/17-4, Lawrance Road, Delhi-110035, India E-mail: sachinmakhija25573@yahoo.com 